\title{
El lenguaje del ser y la voz de la historia. Estudio en torno a las interpretaciones del fundamento en la filosofía hermenéutica de Hans-Georg Gadamer
}

\section{The language of being and the voice of history. \\ Studies on the interpretations of foundation in Hans-Georg Gadamer's philosophical hermeneutics}

\author{
FRANCISCO DÍEZ FISCHER \\ Universidad Católica Argentina
}

Recibido: 04-01-2009 Aprobado definitivamente: 06-05-2009

RESUMEN

Según la hermenéutica filosófica nuestra pertenencia a la historia y al lenguaje determina paradójicamente nuestra indisponibilidad sobre ellos en tanto les pertenecemos más de lo que ellos nos pertenecen. A partir de este principio, la famosa expresión de Gadamer «el ser que puede ser comprendido es lenguaje» ha generado las más diversas interpretaciones en torno a la estructura ontológica que sostiene su propuesta hermenéutica. Comprender la productividad de esta máxima significa enfrentar el conflicto que tensiona el suelo que nos sostiene entre el lenguaje del entender y el lenguaje de las cosas, y proyectar la resultante sobre la estructura del ser histórico.

PALABRAS CLAVE

HERMENÉUTICA, LENGUAJE, HISTORIA, ONTOLOGÍA 


\begin{abstract}
According to philosophical hermeneutics our belonging to history and language determines our paradoxical unavailability over them as we belong to them more than they belong to us. Based on this principle, Gadamer's famous expression «being that can be understood is language» has raised the most diverse interpretations about the ontological structure that supports the hermeneutical proposal. Understanding the productivity of this maxim means confronting the conflict that shakes the ground which sustains us between language of understanding and language of things, and projecting the result on the structure of historical being.
\end{abstract}

KEYWORDS

HERMENEUTICS, LANGUAGE, HISTORY, ONTOLOGY

EN TORNO A LA CÉLEBRe FóRMula de Verdad y Método «el ser que puede ser comprendido es lenguaje» ${ }^{1}$ se han generado fuertes debates sobre cuáles son, en verdad, los fundamentos de la propuesta hermenéutica de Hans-Georg Gadamer. La potencialidad interpretativa de la frase ha dado lugar a lecturas de corte relativista, pero también otras tantas de carga metafísica radicalmente opuesta. Si atendemos a su recepción histórica encontramos dos impulsos predominantes que se ubican en extremos opuestos. El primero elaborado por Richard Rorty y Gianni Vattimo a fines de la década del ' 90 , y el segundo desarrollado por Jean Grondin en estudios recientes (2001-2004). La primera parte de este trabajo (puntos I-II) estará dedicada a exponer dichas interpretaciones con el objetivo de volver con un horizonte más amplio sobre la tercera sección y final de Verdad y Método donde se enuncia la famosa sentencia. La estructura intencional de esta obra deja al descubierto que los análisis de los distintos modos de experiencia hermenéutica (estética, histórica y lingüística) que la conforman, constituyen cada uno un capítulo preparatorio del siguiente. De manera que su hilo conductor se sostiene sólo si existe cierta correspondencia estructural entre el ser del arte, de la historia y del lenguaje. Sobre esta correlación de experiencias, se funda la validez de la parte final de nuestro trabajo (punto III). A partir de la resultante de la tensión metafísica contenida en el eslogan hermenéutico, haremos un camino inverso desde la tercera hacia la segunda parte de Verdad y Método para realizar un análisis retrospectivo del ser histórico.

\title{
I. EN LA TIERRA DESCONOCIDA DEL LENGUAJE
}

Las lecturas que Rorty y Vattimo hacen de la famosa frase «el ser que puede ser comprendido es lenguaje» abren amplitudes bien diferentes sobre la pretensión de Gadamer de convertir a la hermenéutica en filosofía. Para Rorty,

1 H.-G. Gadamer, «Wahrheit und Methode», en Gesammelte Werke I. Tübingen: Mohr (Paul Siebeck), 1990, p. 478; traducción al español: Verdad y Método, traductores A. Agud y R. de Agapito. Salamanca: Sígueme, 1977, p. 567. De ahora en más serán citadas como WM y VM respectivamente. 
a quien se le puede llamar con ciertas reservas el Gadamer americano, la sentencia representa la solución a la discusión actual de la filosofía analítica, ya que logra difuminar los límites entre las ciencias de la naturaleza y del espíritu. La frase «contiene toda la verdad del nominalismo y, a la vez, toda la verdad del idealismo». ${ }^{2}$ Por un lado, constituye el mejor compendio del nominalismo en tanto que la universalidad lingüística propuesta por Gadamer no sólo alcanza a las ciencias del espíritu sino también a las ciencias de la naturaleza. Toda vez que comprendemos algo, incluso cuando estas ciencias captan el mundo físico, lo hacemos siempre con ayuda de una descripción, de modo que no hay posibilidad de salir de nuestro lenguaje y llegar hasta el objeto. La distinción entre para nosotros y en sí es sólo un resto que queda del vocabulario de la metafísica. Lo que para los metafísicos es una aproximación a la naturaleza de las cosas para los nominalistas, y según Rorty también para los hermeneutas, es una «invención de un discurso en el marco del cual se añaden nuevos predicados a las cosas que hasta entonces se definían con viejos predicados». ${ }^{3}$ Por otro lado, la expresión resume toda la verdad del idealismo, en tanto «la tesis principal del idealismo dice que la verdad no se define por la coincidencia con la naturaleza interior del objeto sino por medio de la coherencia». ${ }^{4} \mathrm{Si}$ bien esta tesis no concuerda exactamente con la del nominalismo va según Rorty en la misma dirección al sustituir el concepto de naturaleza interna por el de descripción identificadora. Según su interpretación, al suplantar la metáfora de la profundidad por la de la amplitud, el aumento de la comprensión que Gadamer propone no refiere a un descubrimiento de la naturaleza interna del objeto como una penetración más profunda por la que nos alejamos de la apariencia y nos acercamos a la realidad, sino a que cuanto más descripciones haya en oferta y cuanto mejor estén integradas unas con otras, tanto mejor comprenderemos el objeto que estas descripciones nos transmiten. Así la visión de una esencia real y de la verdad como correspondencia van de la mano, se sostienen y caen juntas; «el eslogan de Gadamer nos da la posibilidad de eliminar las dos visiones». ${ }^{5}$

En el viejo continente, a Gianni Vattimo se le suele llamar el Gadamer italiano, con menos reservas en tanto fue su discípulo directo y traductor de Verdad y Método. Su lectura parece ser más exigente y audaz al sugerir intercalar

2 R. Rorty, «El ser que puede ser comprendido es lenguaje», en El ser que puede ser comprendido es lenguaje. Homenaje a Hans-Georg Gadamer. Madrid: Ed. Síntesis, 2003, p. 45.

3 Ibid., p. 49.

4 Ibid., p. 48.

5 Ibid. Para tener una visión más completa de los puntos y contrapuntos que pueden encontrarse entre Gadamer y Rorty remito al trabajo de María Teresa Muñoz Sánchez, «El ser que puede ser comprendido es lenguaje. Una mirada a Gadamer desde Rorty», Contrastes, XIII (2008), pp.7-18. 
una coma de manera que la frase deba ser leída: «El ser, que puede ser comprendido, es lenguaje». El original alemán dice «Sein, das verstanden werden kann, ist Sprache», pero no deja de ser ambiguo ya que las reglas de puntuación alemana a diferencia del inglés y de los idiomas latinos no permiten distinguir los diversos modos de determinación que tiene una oración de relativo: 1) como oración especificativa cuando restringe en un sentido esencial al sujeto al que ella se refiere como si dijéramos: 'La filosofía que no es sabiduría es inauténtica' o 2) como oración explicativa cuando determina en un sentido no esencial una cualidad del sujeto, por ejemplo: 'La persona, que está sentada al fondo, está durmiendo'. La frase suele ser leída, incluso por el mismo Gadamer, como oración especificativa, de manera que el ser que es lenguaje es sólo el ser que puede ser comprendido. Pero, interponiendo la coma Vattimo se inclina hacia el sentido explicativo, así ser y lenguaje son lo mismo. No obstante, contrariamente a Rorty, Vattimo no aboga por una pura arbitrariedad. A su juicio, Gadamer no describe un estado de cosas, ni se limita a mostrar qué pasa en las ciencias del espíritu, sino que, a la luz de su propia historia efectual, parece hacer una propuesta ética en el sentido de la distinción de existencia auténtica e inauténtica propuesta por Heidegger en Ser y Tiempo. «Lo que quería decir la resolución precursora de la muerte en Heidegger [...] lo aprendemos de modo mucho más claro en estas páginas de Gadamer. Como es sabido, en Ser y Tiempo es la resolución propia para la muerte lo que hace posible comprender el pasado, no como vergangen, sino como gewesen, esto es, como posibilidad todavía abierta. Traducido a los términos de Gadamer, esta actitud auténtica (eigentliche) significa que el legado al que nos referimos para examinar nuestros prejuicios y reconocer los que son legítimos y productivos consiste en no verlo como una estructura eterna del ser metafísico, que debemos reflejar fielmente y al que debemos adecuarnos (ni menos aún como la objetividad 'ahí afuera' de los 'objetos'), sino como legado puramente histórico de unos mortales a otros mortales». ${ }^{6}$ Cada interpretación cambia el mundo, por eso para Vattimo el núcleo de la ontología hermenéutica es la identificación entre interpretar el mundo y transformarlo actuando históricamente, es decir, la identificación de realidad (Wirklichkeit) e historia efectiva (Wirkungsgeschichte). Así deberíamos entender el sentido moral que tiene el giro ontológico del que habla Gadamer en la última sección de Verdad y Método, y la actitud auténtica contenida en la máxima hermenéutica como un debilitamiento de nuestro discurso sobre el ser. Según Vattimo, Gadamer

6 G. Vattimo, «Comprender el mundo-transformar el mundo», en El ser que puede ser comprendido es lenguaje. Homenaje a Hans-Georg Gadamer. Madrid: Ed. Síntesis, 2003, p. 66. 
ha querido asimilar ser y lenguaje, pero sin extraer todas las consecuencias ontológicas de esta fusión que están más allá de la hermenéutica?

Ahora bien cabe la pregunta ¿hasta qué punto estas dos lecturas son palabras justas para con la hermenéutica de Gadamer? La corrección y justeza parecen venir de Gadamer mismo toda vez que habla de una fusión del entender y su objeto o cuando afirma que el lenguaje determina no solamente el proceso, sino también el objeto hermenéutico. De manera que parece estar proponiendo un relativismo lingüístico en el que lo que es depende en su ser del lenguaje. Pero para dar toda la dimensión a la respuesta, es necesario escuchar también las consideraciones que Jean Grondin hace a este respecto y que van en la dirección contraria.

En un trabajo titulado Qué significa «el ser que puede ser comprendido es lenguaje», Grondin sigue, como hizo Vattimo, la pista de la historia efectual que anima la frase. Si elimináramos la oración subordinada y la expresión fuese sencillamente «el ser es lenguaje», sin duda sería un pensamiento lleno de sentido para Heidegger en tanto que solamente el hombre como esencia lingüística tiene acceso al Ser. Esta semántica heideggeriana no es totalmente extraña al dicho de Gadamer. Sin embargo que el acento esté puesto no en el ser, sino en el ser que puede ser comprendido, es decir, que la oración de relativo sea entendida como especificativa, no significa que el ser es lenguaje, sino que el ser comprendido tiene necesariamente carácter lingüístico. De lo que se trata aquí para Grondin no es tanto de «una tesis ontológica sobre el ser, o el ser en sí [...] sino [de] una tesis sobre nuestro comprender, es decir, que la comprensión humana no puede prescindir de la lingüisticidad». ¿ ¿Se puede acaso pensar sin palabras? Más bien palabra y pensamiento acontecen al mismo tiempo. Cuando pensamos, nuestro pensar va indisociablemente unido al lenguaje. Esta interpretación coincide con la dirección argumentativa que Gadamer asume en Verdad y Método para dejar en evidencia la historia del olvido del lenguaje en su unidad con el pensamiento y mostrar la radical lingüisticidad de nuestra experiencia del mundo. Sin embargo, aún no queda claro si esta íntima co-pertenencia de pensar y lenguaje puede «volver a las cosas mismas» que es la clave fenomenológica en el diálogo hermenéutico con las interpretaciones de Rorty y Vattimo.

7 G. Vattimo, Au-delà de l'interprétation. La signification de l'herméneutique pour la philosophie. Paris, Ed. De Boeck, 1997, p. 21.

8 J. Grondin, «Was heisst 'Sein, das verstanden werden kann, ist Sprache'?», en Von Heidegger zu Gadamer. Unterwegs zur Hermeneutik. Darmstadt: Wissenschaftliche Buchgesellschaft, 2001, p. 103. 


\section{El LENGUAJE DE LAS COSAS: LA FUERZA ONTOGENÉTICA DE SU PALABRA}

A los puntos y contrapuntos de esta confrontación exegética, se suman las observaciones que Grondin hizo algunos años más tarde en un trabajo de homenaje titulado El legado de Gadamer. Frente al acento que Rorty y Vattimo habían puesto sobre el lenguaje como determinante o imperativo fluidificante del ser, Grondin propuso correr el peso hacia el otro extremo de la frase como si fuese «el ser mismo el que accediera a su inteligibilidad en el lenguaje».? Ya no se trata sólo del lenguaje del entender en la fusión de horizontes entre la comprensión y su lenguaje, es decir, de la lingüisticidad de nuestro comprender, sino que la conocida expresión hermenéutica está aludiendo a otra fusión «quizás más discreta, pero no menos importante», la fusión del ser y del lenguaje. Vattimo ya ha visto esta misma fusión pero desde el costado lingüístico. El cambio de acento transmuta la carga metafísica de la interpretación, de manera que ella parece indicar ahora que no hay solamente el lenguaje del comprender, es decir, nuestro lenguaje, sino un lenguaje del ser, propio de las cosas mismas, que Gadamer llama die Sprache der Dinge.

Intentar develar en qué consiste este lenguaje requiere al menos dos caminos: 1) la apelación a lo dicho en expresiones lingüísticas cotidianas referidas al lenguaje y a las cosas, y 2) el análisis de la eficacia histórica de estas frases en el contexto de la filosofía. A mbos recursos fueron desplegados por Gadamer en una conferencia titulada Die Natur der Sache und die Sprache der Dinge, dictada curiosamente el mismo año en que se publicó Verdad y Método, como si hubiese querido ser una suerte de apéndice aclaratorio. ${ }^{10}$ La consideración del problema comienza con la referencia a dos expresiones usuales: «eso está en la naturaleza de las cosas» y «las cosas hablan por sí solas». Ambas fórmulas parecen aducir no necesitar de razones para dar algo por verdadero. Pero según Gadamer la cuestión está en saber a qué nos estamos refiriendo, en verdad, cuando hacemos uso de ellas. Si tomamos el término cosa, que es común a ambas, sabemos que, en general, se especifica en contraposición al término persona para dar a entender una preeminencia del segundo sobre el primero, en tanto la persona debe ser estimada en su propio ser, mientras que la cosa es un útil a nuestra disposición. Sin embargo, observa que cuando decimos que algo está en la naturaleza de una cosa, la expresión indica que lo que está ahí para nuestra utilidad posee en realidad un ser en virtud del cual puede oponer resistencia al

9 J. Grondin, «El legado de Gadamer», en J. J. Acero, J. A. Nicolás, J. A. P. Tapias, L. Sáez, J. F. Zúñiga (eds.), El Legado de Gadamer. Granada: Ed. Universidad de Granada, 2004, p. 22.

10 Conferencia pronunciada en Munich durante el VI Congreso Alemán de Filosofía (1960). Aparece en las actas del congreso publicada bajo el título Das problem der Ordnung; un título sugerente para la dirección de nuestra investigación. 
uso incorrecto; o en sentido positivo, por su propia naturaleza nos puede imponer y exigir un determinado comportamiento (algo que se evidencia en el término alemán Sachverhalt ${ }^{l 1}$ ). Entonces, se invierte la usual preferencia y la cosa pone de manifiesto su carácter de resistencia con el que es preciso contar y su matiz desinteresado (opuesto al sentido utilitario más frecuente) desde el momento en que le atribuimos un comportamiento propio que exige plegarnos al suyo. Pero la historia de la filosofía deja en claro que la expresión «naturaleza de la cosa» tiene un prontuario semántico lo suficientemente polémico como para tener suficientes reservas respecto de su uso. El largo prospecto de sus contraindicaciones no pasa desapercibido a Gadamer que considera que la apelación a esta naturaleza como al en sí de la cosa está viciada del mismo presupuesto que la posición idealista a la que ella combate. El supuesto consiste en contraponer la subjetividad humana al ser en sí y considerar que ella es «una voluntad que se impone sin discusión, incluso cuando el ser en sí se manifiesta como límite a la determinación por la voluntad». ${ }^{12}$ Dicha oposición comienza a erigirse sobre la destrucción de una correspondencia originaria para ponerse en seguida como condición de dominación sobre el real subsistente en sí. De este modo, detrás del concepto de «ser en sí» se perfila una oposición entre sujeto y objeto que funciona como presupuesto del conocimiento objetivo y de las ciencias de la naturaleza. Estas consideraciones «antimetafísicas» muestran que la conciencia histórica de Gadamer nos impide entender su proposición hermenéutica como una reducción del ser a la subjetividad absolutizada. Pero nos resta todavía ver si ella no reduce el yo al ser (reducción que supone también una separación) como hace según Vattimo toda «metafísica tradicional» 0 «realismo naif». ${ }^{13}$ Para esclarecer su postura debemos analizar la otra expresión del lenguaje cotidiano «las cosas (Dinge) hablan por sí mismas» que refiere a su lenguaje y nos ubica ante una referencia significativa semejante, en tanto es un hablar al que no se lo escucha lo suficiente, y que confirma que, en general, no estamos dispuestos a considerar las cosas en su propio ser.

11 El comportamiento (Verhalt) de una cosa (Sache) «no designa algo disputado entre las partes, sino los límites que pone al libre albedrío el legislador con su ley [...] invoca un orden sustraído al arbitrio humano [...] algo que se hace valer, algo que debe respetarse». Este significado jurídico lo hereda de la causa latina de la que a su vez deriva la palabra castellana cosa. H.-G. Gadamer, «Die Natur der Sache und die Sprache der Dinge», en Gesammelte Werke II. Tübingen: Mohr (Paul Siebeck), 1993, p. 67; traducción al español «La naturaleza de la cosa y el lenguaje de las cosas», en Verdad y Método II, traductor M. Olasagasti. Salamanca: Sígueme, 1998 , p. 72.

12 Ibid., p. 70; p. 75.

$13 C f$. G. Vattimo, «Historia de una coma. Gadamer y el sentido del ser», Endoxa: Series Filosóficas, $\mathrm{n}^{\circ} 20$ (2005), pp. 45-62. 
Recurriendo a la voz de la historia, Gadamer remonta el sentido de esta expresión hasta la co-pertenencia de palabra y cosa planteada en los inicios de la filosofía. La rectitud de los nombres que los griegos sostenían era quizás el último eco de la antigua función mágica de las palabras que era comprendida como la cosa misma y como su ser constitutivo y, en la historia bíblica, un eco del poder de nominación que tenía su origen en la tarea adámica. En verdad, el auténtico origen histórico de esta ligación se nos escapa desde siempre, pero su unión indisoluble es la que «confiere al lenguaje su eficacia». ${ }^{14}$ Sabemos también que la filosofía griega deshizo lentamente este poder del lenguaje. Según Gadamer, Platón degradó el ser de la palabra a un puro aspecto exterior al pensamiento y marginalizó su función en el camino de acceso a la verdadera realidad inaugurando «la historia del olvido del lenguaje». ${ }^{15} \mathrm{El}$ heredero cristiano de la metafísica griega, el medievo escolástico, tampoco parece haber captado, según Gadamer, el enigma de este lenguaje de las cosas, es decir, la íntima co-pertenencia entre ser y palabra. Continuó encubriendo la lingüisticidad de la experiencia del ser al concebir que el verdadero ser de las cosas (su en sí) eran esencias accesibles al espíritu (para nosotros) de forma directa e independiente del lenguaje.

Hay que reconocer que la dificultad para entender este hablar del ser no es sólo a causa de una marginación y olvido histórico por parte de la metafísica. En Verdad y Método, la recapitulación que Gadamer mismo hace de la historia filosófica de esta idea, cuenta con exposiciones brevemente esbozadas y encuentra al lector tan poco preparado que parece extraña su referencia conclusiva a una cierta superioridad de la metafísica clásica respecto de este problema. Cabe aclarar que cuando Gadamer habla de «metafísica clásica» alude, especialmente, a la doctrina de los trascendentales, a la metafísica de la luz y a la idea cristiana de la Encarnación de la Palabra que hace de Agustín de Hipona la extraña excepción en este camino de olvidos. ${ }^{16}$ ¿Cuáles son las ventajas de estas

14 Cf. D. Frey, L'interprétation et la lecture chez Ricoeur et Gadamer. Paris: PUF, 2008, pp. 136 ss.

15 Para la crítica de Gadamer a Platón $c f$. WM, pp. 411 ss.; VM, pp. 489 ss. También conviene señalar la revaloración que Gadamer mismo hace del pensamiento platónico a partir de la noción de belleza precisamente en el marco de la fundamentación de la universalidad filosófica de su propuesta hermenéutica. $C f$. H.-G. Gadamer WM, pp. 478 ss.; VM, pp. 567 ss. Esta revalorización está presente también en muchos de sus trabajos sobre Platón: tomos V-VII de sus Gesammelte Werke.

16 Para las influencias de Agustín en la ontología de Gadamer $c f$. J. Grondin, «Gadamer und Augustin. Zum Ursprung des hermeneutischen Universalitätsanspruchs», en Der Sinn für Hermeneutik. Darmstadt: Wissenschaftliche Buchgesellschaft, 1994, pp. 24-39; y mi trabajo, «El recuerdo del lenguaje», IV Boletín de estudios de filosofía y cultura Manuel Mindán, (Diciembre de 2008), pp. 195-211. 
antiguas doctrinas para pensar el lenguaje del ser? Para Gadamer, la primera y principal es que aún no concebían el conocer como un dominar, sino como una participación en el ser y la verdad, precisamente porque entendían que en la estructura ontológica lo primario es ser en relación. «En la metafísica [clásica], la pertenencia se refiere a la relación trascendental entre el ser y la verdad, que piensa el conocimiento como un momento del ser mismo, no primariamente como un comportamiento del sujeto. Esta inclusión del conocimiento en el ser es el presupuesto del pensamiento antiguo y medieval». ${ }^{17}$

Gadamer hace de esta idea de pertenencia y participación el hilo conductor de las tres esferas de experiencia hermenéutica (estética, histórica y lingüística) que componen la estructura más profunda de Verdad y Método. ${ }^{18}$ Pero aunque la experiencia del juego en la esfera estética, la experiencia de la tradición en la esfera histórica y la experiencia del diálogo en la esfera del lenguaje indiquen, del mismo modo que en la metafísica clásica, la co-pertenencia del ser, es decir, un ser «más allá del dualismo de la subjetividad-voluntad de un lado, y del objeto ser en sí del otro, pensándolos como la correspondencia previa de lo uno y lo otro», ${ }^{19}$ habrá todavía un problema fundamental: en la metafísica clásica la noción de pertenencia tiene un fundamento teológico. El alma y la cosa se reúnen en su condición de creadas por un intelecto infinito y la filosofía no puede utilizar ya esta justificación religiosa, pero tampoco tiene, según Gadamer, «el derecho de cerrarse a la verdad de esta correspondencia». ${ }^{20}$ Entonces, si tuviéramos la intención de sostener la mutua copertenencia del «ser que comprende y del ser comprendido», que funda el carácter de acontecimiento de la experiencia hermenéutica, deberíamos investigar la posibilidad de un fundamento finito de esta correspondencia relacional del ser.

El interrogante podría despertar dudas sobre si el intento hermenéutico no consiste en una restitución secular de la metafísica clásica. Nuestro autor no parece pensar tan a espaldas de la historia. Es cierto que en Verdad y Método sus reflexiones sobre metafísica son esporádicas como si la labor crítica de su maestro Heidegger hubiese erigido en él un escrúpulo que le impidiese usar el término con libertad (como muchos postheideggerianos prefiere utilizar la palabra ontología). Sin embargo, él mismo sugiere que la tarea metafísica se ha transformado en los últimos años gracias al reconocimiento de la finitud e historicidad de la existencia humana llevado a cabo también por Heidegger y del significado autónomo del lenguaje hablado que hizo desaparecer el talante

17 H.-G. Gadamer, WM, p. 462; VM, p. 549.

18 Cf. P. Ricoeur, Del Texto a la Acción. Buenos Aires: FCE, 1986, pp. 309 ss.

19 H.-G. Gadamer «Die Natur der Sache und die Sprache der Dinge», p. 68; «La naturaleza de la cosa y el lenguaje de las cosas», p. 75 .

20 Ibid. 
antimetafísico del positivismo lógico (Wittgenstein). Hoy estos aportes parecen haber vuelto posible la reactualización de la verdad de aquella relación originaria de pertenencia y la formulación un nuevo modo de su fundamentación que Gadamer cree ver elevarse en el horizonte presente del pensamiento filosófico: «hay un camino al que apunta la filosofía cada vez con más claridad y que da testimonio de esa correspondencia. Es el camino del lenguaje». ${ }^{21}$

Así volvemos a encontrar la pista del lenguaje del ser y se renueva la cuestión sobre «si el lenguaje no debe ser en definitiva 'lenguaje de las cosas' -si queremos pensar realmente algo- y si no es el lenguaje de las cosas el que pone de manifiesto la correspondencia originaria entre alma y ser, de tal modo que incluso una conciencia finita pueda saber algo de ella». ${ }^{22}$ Así el tercer término del famoso eslogan se convierte en la posibilidad de dar razón de la reunión entre el ser comprendido y el ser que comprende, no en su significado reducido como lenguaje del entender, sino en su fusión con el ser como lenguaje de las cosas. De manera que la preposición «de» indica en los dos casos la determinación de la relación epistemológica y ontológica entre ser y comprender como una previa y siempre más originaria co-pertenencia de ambos al lenguaje.

\section{II.1. LA LUMINOSIDAD ONTOGENÉTICA DEL LENGUAJE}

$\mathrm{Si}$, como sugiere Grondin, la correspondencia entre la comprensión y su objeto se funda en una fusión más originaria que la del entender y el lenguaje, es decir, la que ocurre entre el ser y la palabra, queda todavía por aclarar qué es lo que, en verdad, acontece en ella. Para ello volvamos, por un momento, sobre una de las referencias medievales a las que Gadamer hace alusión: la metafísica de la luz. Al ser de la luz le corresponde una naturaleza reflexiva, ya reconocida por el pensamiento estoico. ${ }^{23}$ La reflexión es un fenómeno de origen óptico: la luz al iluminar posibilita nuestra visión, le da carácter visible a las cosas y, al mismo tiempo, en esa iluminación se hace visible ella misma. La referencia a tal propiedad no es improvisada por Gadamer. El lenguaje tiene la misma cualidad reflexiva. Ya sabemos por la fusión entre lenguaje y comprensión que la palabra no solamente posibilita nuestro comprender sino que éste se cumple en ella. Pero ahora, al igual que la luz, la palabra es además la condición de posibilidad del aparecer de la cosa y de su carácter comprensible, precisamente porque «la luz, que hace que las cosas aparezcan de manera que sean en sí mismas luminosas y comprensibles, es la luz de la palabra». ${ }^{24} \mathrm{Y}$ esta

21 Ibid., p. 69; p. 76

22 Ibid.

23 Cf. Stoic. Vet. Fragm. II 24, 36, 9.

24 H.-G. Gadamer, WM, p. 487; VM, p. 577. La referencia coincide con la herencia agustiniana de la encarnación del Verbo y con el antiguo carácter medieval de la 
es la más fundamental potencialidad lingüística: un previo quedar abarcado todo ente por su posibilidad de venir al lenguaje y, por tanto, al mundo. La eficacia ontogenética de su reflexividad consiste en hacer «salir el ser al mundo» ${ }^{25}$ es la articulación misma de la presencia de las cosas (Sachlichkeit) como donado fenomenológico. ${ }^{26}$ En virtud de esta potencialidad se establece la íntima copertenencia que acontece como fusión entre ser y lenguaje a tal punto que se vuelve imposible distinguir el ser mismo de su presencia en la palabra y separarlo de aquello que le da voz. Por ella el ser viene al lenguaje y el lenguaje se vuelve visible a sí mismo como lenguaje del ser (de manera que el ser del lenguaje es ya siempre lenguaje del ser). En la experiencia hermenéutica, forma lingüística y contenido transmitido son inseparables. De tal manera que sólo podremos refutar una ontología de este tipo si encontramos un ser o una experiencia de él que esté más allá de la fusión reflexiva del lenguaje, es decir, que no esté ya él mismo orientado hacia una inteligibilidad lingüística. ${ }^{27}$ Pero, lo cierto es que incluso el ser que experimento sin decir una palabra, permanece anclado en el lenguaje, en la medida en que es visto o sentido como esto o aquello.

La cualidad reflexiva de la luz de la palabra irradia ahora de una forma nueva sobre la fusión del entender y el lenguaje, y pone de relieve otro aspecto. No sólo, como ya hemos visto, su luz posibilita nuestro comprender (función epistemológica), sino que además permite «que incluso una conciencia finita pueda saber algo de ella» porque nuestro propio ser es el que aparece y se hace comprensible gracias al lenguaje (función ontológica). De este modo el conocimiento y el aparecer de nosotros y de las cosas implica siempre la palabra; y por eso incluso cuando hablamos de nosotros mismos podemos decir con verdad que «todo ser que puede ser comprendido ya está de camino al lenguaje». ${ }^{28}$ Pensamiento y ser están íntimamente unidos en la luz de la palabra, de manera que en la co-pertenencia de los tres sustantivos de la expresión hermenéutica:

palabra como speculum que hace patente la cosa misma en la identidad entre lenguaje y pensamiento.

25 J. Grondin, L'hermenéutique. Paris: PUF, 2006, p. 64.

26 El centro fundamental de la hermenéutica como filosofía es esta fenomenalidad lingüística del ser. Quizás la posibilidad misma y la necesidad de un cuestionamiento metafísico de la hermenéutica se apoya sobre suelo fenomenológico. Una de las consecuencias ontológicas de esta fusión que, al decir de Vattimo, están «más allá de la hermenéutica» podría ser que la hermenéutica conduce a la fenomenología y viceversa. $C f$. G. Deniau, Cognitio imaginativa. La phénoménologie herméneutique de Gadamer. Bruxelles: Éditions OUSIA, 2002, p. 457, y también $c f$. J. Grondin, Le tournant herméneutique de la phénoménologie. Paris: PUF, 2003.

27 Cf. J. Grondin, Introducción a la metafísica. Barcelona: Herder, 2006, p. 367.

28 J. Grondin, Introducción a la metafísica, p. 367. Cf. H.-G. Gadamer, «Mensch und Sprache», en Gesammelte Werke II, pp. 146-154; traducción al español: «Hombre y Lenguaje», en Verdad y Método II, pp. 145-152. 
ser y comprender estarían mediados por el término lenguaje; y todos deben ser tomados en su máxima extensión. Además la reversibilidad del tercer término queda manifiesta: nos pertenece en tanto lo hablamos y con él interrogamos a las cosas, pero también, más radicalmente, pertenecemos a él y nos tiene prendidos, porque nuestro hablar está invitado a escuchar y plegarse al hablar de las cosas. Esta particular herencia de la metafísica clásica ayuda a entender el alcance de esa «solidaridad preinstrumental del ser y de la palabra $»^{29}$ y el fundamento de la estrecha relación que existe entre la patencia de lo bello y la evidencia de lo comprensible que, como Gadamer reconoce, ha orientado en parte su planteamiento hermenéutico.

Tal como hasta aquí parece entenderlo nuestro autor, la famosa máxima esconde la sutil referencia al lenguaje de las cosas que justamente no habla de si (como sí lo hace nuestro lenguaje para el nominalismo) sino que habla «de lo que es o presumiblemente es». ${ }^{30}$ De manera que si ahora retomáramos el análisis del comienzo, la expresión parecería reubicarse en el extremo opuesto a la interpretación hecha por Rorty de ser una síntesis acabada del nominalismo. La reflexividad de la fusión entre ser y palabra sobre la que se funda la correspondencia entre ser y comprender, es la que suprime el nominalismo, pues quiebra la relación de pertenencia previa y separa al ser que comprende del ser comprendido, convirtiendo a todo ser (a las cosas, pero, por lo tanto, también a nosotros mismos) en infinitamente dominable y disponible al poder de nuestro lenguaje (ya descargado de su eficacia ontogenética).

\section{II.2. DEL CIELO DE LOS TRASCENDENTALES A LA PREHISTORIA DE LA METAFÍSICA}

Ahora bien «cuando rebasamos el concepto del objeto y de la objetividad de la comprensión en dirección a una mutua pertenencia de lo subjetivo y de lo objetivo, nos limitamos a guiarnos por la necesidad de las cosas», ${ }^{31}$ es decir, que seguimos un comportamiento que ellas mismas nos exigen al venir a la presencia en la palabra y que está en concordancia con la copertenencia ontológica que funda el lenguaje. Pero aquí parece esconderse aún una solidaridad más profunda de la metafísica clásica para con la hermenéutica. Según Grondin, en su otra herencia, la doctrina de los trascendentales, algo parece fascinar a Gadamer. Como predicados universales las propiedades trascendentales son

30 H.-G. Gadamer, «Historik und Sprache», en Gesammelte Werke X. Tübingen: Mohr (Paul Siebeck), 1995, p. 329; traducción al español: «Histórica y lenguaje: una respuesta», en R Koselleck y H.-G. Gadamer, Historia y hermenéutica, traductor F. Oncina. Barcelona: Paidós, 1997, p. 106.

31 H.-G. Gadamer, WM, p. 465; VM, p. 552. 
siempre propiedades del ser mismo, es decir, comunes a todo ser en absoluto (a diferencia de los predicamentales). No son jamás propiedades de una subjetividad o del conocimiento. De modo semejante, la universalidad filosófica de la hermenéutica parece indicar que el lenguaje como «lenguaje de las cosas» tampoco sería la propiedad de un sujeto sino que «expresa en principio y ante todo la presencia del ser en el espíritu, mediante la luz del lenguaje que precede a todo pensamiento». ${ }^{32} \mathrm{Si}$ repasamos esta antigua doctrina se aclarará el sentido de las posibles correspondencias. Las propiedades trascendentales que convienen a todo ser considerado en sí mismo son res y unum; y en cuanto convienen a todo ser considerado en orden a otro debemos ver si la relación es de división o de conformidad con ese otro. Si es una relación de separación lo expresa aliquid, y si es una relación de conformidad ese otro sólo puede ser, en esta doctrina, el alma en la medida en que «ella puede ser todas las cosas». La conformidad del ser con la facultad apetitiva del alma lo expresa el trascendental bonum y con la facultad cognoscitiva lo expresa verum. ${ }^{33} \mathrm{Si}$ la historia de la metafísica permitiese hoy agregar una nueva estrella al cielo de los trascendentales, el lenguaje sería una propiedad del ser en orden a otro, más precisamente en la relación de conformidad previa y originaria del ser con el alma, que se corresponde con lo que pone de manifiesto la pertenencia ontológica y la reflexividad de su luz. Tal vez habría que ver aún en qué sentido sería convertible (convertuntur) y si esa conversión no mostraría que, en comparación con los antiguos modos relacionales de concordancia, el lenguaje tiene una amplitud en la que éstos podrían quedar abarcados. Lo cierto es que hasta aquí el carácter trascendental del lenguaje se evidencia doble: (1) en el sentido medieval, como propiedad o modo del ser (2da fusión), pero también (2) en el sentido moderno, en tanto es condición de posibilidad de nuestro comprender (1era fusión). Es bien curioso que de la mano de los trascendentales medievales Gadamer haga su intento de superar la filosofía trascendental de los modernos fundada en la supremacía soberana del sujeto.

El camino de la historia de la metafísica es largo y la hermenéutica recoge aún otra herencia más antigua que la medieval, que extiende sus raíces hasta su propia prehistoria. Una tradición cuya verdad, a los ojos de Gadamer, ya supo oír Hegel cuando eligió como párrafo final de su sistema de la ciencia filosófica un texto griego tomado de la Metafísica de Aristóteles. La frase dice: «Lo más digno son las estrellas» (980, b 23-25). La referencia suena extraña en tanto parecería que entre todas las cosas del mundo, el hombre debería ser considerado, en verdad, lo más digno. Pero, la preferencia deja ver un nuevo sentido de racionalidad que procede de los más remotos tiempos de los griegos;

32 J. Grondin, Introducción a la metafísica, p. 368.

33 Cf. Tomás de Aquino, Summa Theologica, I p., V, XVI. 
a saber, que la racionalidad del ser (la gran hipótesis de la filosofía griega) es «una cualificación menos de la autoconciencia humana que del ser mismo, que es el todo y se muestra como el todo, de modo que más bien es la razón humana la que ha de verse a sí misma como una parte de aquella, en vez de cómo una autoconciencia que se opone al todo». ${ }^{34}$ Hay aquí una correspondencia evidente con el «ser en relación de pertenencia» de la metafísica clásica y con el carácter trascendental del lenguaje que se deja ver desde nuestro comprender. La relacionalidad del todo es el sentido más originario de toda racionalidad. Cada presencia y su experiencia son relacionales porque ellas advienen en el logos, es decir, en el lenguaje. Y la universalidad del lenguaje es entonces una «nueva» universalidad del logos porque «ahora estamos en condiciones de comprender que este giro del hacer de la cosa misma, del acceso del sentido al lenguaje, apunta a una estructura universal-ontológica, a la constitución fundamental de todo aquello hacia lo que puede volverse la comprensión». ${ }^{35}$ Así el logos griego es la herencia más antigua de la comprensión del lenguaje como articulación de la totalidad (el tejido relacional de toda presencia). Podemos decir que quizás él es la influencia persistente, la eficacia histórica de la hermenéutica, pues según Gadamer es con el «giro hacia los lógoi» que la filosofía ha encontrado por primera vez su objeto propio, es decir, la totalidad. ${ }^{36}$ De modo que hoy la filosofía contemporánea parece encontrar en el lenguaje una nueva refundación precisamente hermenéutica; y viceversa, la hermenéutica reencuentra su vocación metafísica, es decir, cumple su pretensión de universalidad como filosofía, reflexionando hasta el final sobre la universalidad del lenguaje. ${ }^{37}$

La antigua hipótesis reactualizada significaría que la condición de nuestro lenguaje sigue siendo ser parte de y estar llamado a responder al hablar de las cosas mismas que es la formulación hermenéutica que podemos dar al lema fenomenológico. ${ }^{38}$ Aquí se oye la prehistoria de la metafísica que al entender de

34 H.-G. Gadamer, Hermeneutische Entwürfe. Tübingen: Mohr (Paul Siebeck), 2000, p. 23; traducción al español: Acotaciones hermenéuticas, traductores A. Agud y R. de Agapito. Madrid: Ed. Trotta, 2002, p. 36.

35 H. G. Gadamer, WM, p. 478; VM, p. 567.

$36 C f$. H. G. Gadamer, «Philosophie und Poesie», en Gesammelte Werke VIII. Tübingen: Mohr (Paul Siebeck), 1993, pp. 237-8; traducción al español: «Filosofía y poesía», en Estética y Hermenéutica, traductor Antonio Gómez Ramos. Madrid: Tecnos, 1998, p. 179.

37 En esta misma dirección se ubica la interpretación de Deniau cuando sostiene que la fórmula «el ser se da como logos» es el ancestro de la expresión «el ser es lenguaje». De modo que la huída hacia los lógoi que inaugura la actividad filosófica «no es ninguna otra cosa que esta toma de conciencia de la universalidad de la dimensión lingüística». Desde este punto de vista, la hermenéutica filosófica no dice nada nuevo. Cf. G. Deniau, op. cit., p. 454.

38 Gadamer mismo considera que «la fenomenología, la hermenéutica y la metafísica no son tres puntos de vista filosóficos distintos, sino el filosofar mismo». H.-G. Gadamer, «Phänomenologie, Hermeneutik, Metaphysik», en Gesammelte Werke X, p. 109; traducción al español: 
Gadamer nace en Parménides y se resume en una máxima familiar a la sentencia hermenéutica: «el ser no se expresa en el pensar, sino el pensar en el ser». ${ }^{39}$ $\mathrm{Y}$ «esto no es arcaico en el sentido de que aquí aún no se ha pensado hasta el fin, sino en el sentido de que aquí aún se piensa inicialmente. Estos arcaísmos manifiestan en su interna copertenencia una cercanía con lo inicial, es decir, a una experiencia del ser que posibilita toda metafísica. Ella alcanza, en verdad, no solamente hasta Aristóteles y la forma escolástica de la metafísica; alcanza más bien hasta sus confines y más allá de ellos» ${ }^{40}$ y probablemente, lo alcanza a Gadamer mismo.

\section{II.3. EL MOVIMIENTO ORIGINAL DE PERTENENCIA: EL DÍA-LOGOS DEL SER}

Todo el legado de la metafísica clásica y griega nos da mayor conciencia de cuán radical podría ser el sentido del carácter lingüístico de nuestra experiencia del mundo. Sin embargo, a este respecto, todavía queda por ver cuál es la modalidad hermenéutica en que el lenguaje dice el ser (tanto para sí como para nosotros; si aún nos está permitido usar este vocabulario separatista, ya no tan propio de la metafísica). Al entender de Gadamer, el lenguaje no expresa las cosas como si fuese la copia de un ser en sí ya dado y fijado de antemano, como un logos ousías que pudiese darlas a luz de manera perfecta erradicando toda oscuridad. Las dice en el modo finito de aparecer del ser en relación, es decir, que su luz acontece en un constante e interminable diá-logos. «No hay un ser en sí que se va desvelando cada vez un poco más, sino que ocurre como en una verdadera conversación, que surge algo que ninguno de los interlocutores abarcaría por sí solo». ${ }^{41}$ La conversación cumple en el lenguaje el movimiento ontológico primario de interconexión: dar, participar, tomar que nos impide ponernos en la situación separada de un sujeto hablante que comprende frente a un mundo de objetos mudos y dominables. Más bien, conduce a la auto-comprensión como

«Fenomenología, Hermenéutica, Metafísica», en El giro hermenéutico, traductor A. Parada. Madrid: Cátedra, 1998, p. 37.

39 H.-G. Gadamer, «Zur Vorgeschichte der Metaphysik», en Gesammelte Werke VI. Tübingen: Mohr (Paul Siebeck), 1999, p. 25; traducción al español: Hacia la prehistoria de la metafísica, traductor Fabián Mié. Córdoba: Alción Editora, 1992, p. 41.

40 Ibid., p. 29; p. 49.

41

H.-G. Gadamer, WM, p. 466; VM, p. 553. Parece cierto, como dice Rorty, que Gadamer suplanta la metáfora de la profundidad por la de la amplitud, pero ésta sólo se da a entender desde el acontecer del ser y de la comprensión que ocurre en el diálogo; acontecer inesperado e incalculable por nosotros si nos consideramos metafísicamente huérfanos, es decir, como sujetos autónomos y soberanos sin ninguna tierra ontológica de pertenencia. $C f$. Esquivel, O., «Lenguaje, acontecimiento y ser: la metafísica del lenguaje de H. G. Gadamer», en Cuadernos del Sur: Filosofía, no 31-32 (2001-2003), pp. 65-89. 
participantes de un diálogo ontológico de tal dimensión y fuerza que en él acontecen cosas y también nosotros mismos. Es la modalidad del lenguaje que encarna el movimiento universal de esta ontología: el ser diálogo del ser que implica siempre nuestra participación. Entonces queda en evidencia porque el primer título propuesto para Verdad y Método era Comprensión y acontecimiento. La pertenencia originaria del ser y del entender al lenguaje, que esta conversación metafísica evidencia, determina que comprender debe ser una cuestión más de participación y de acontecimiento que de dominio. Al lenguaje de las cosas solo podemos acceder a través de su dimensión comunicativa, que es el diálogo, porque él tiene, más que cualquier otra de las formas lingüísticas, el carácter de ser un acontecer en el que se toma parte y en el que no se oculta la infinitud de todo lo que queda por decir. Por eso, la conversación del ser recoge nuestra dimensión de historicidad, o sea, «percibe nuestra esencia histórica finita», ${ }_{42}$ porque da a luz para y con nosotros totalidades e infinitudes de sentido. Así queda al descubierto el centro de esta «ontología de la pertenencia» que es el carácter especulativo del lenguaje, es decir, la infinitud de todo lo que tendría que decirse para que algo sea entendido rectamente. ${ }^{43} \mathrm{El}$ diálogo permite cumplir algo dicho en correspondencia con el lenguaje de las cosas, es decir, que logre hacer escuchar conjuntamente en lo que dice todo aquello que queda por decir. Por eso, la mudez del mundo no sería una falta de su lenguaje como si padeciese una imposibilidad de conversar, es decir, de hacer aparecer comprensible, y por tanto de acompañar el acontecer de nuestra comprensión.

Si volvemos por un momento sobre la modalidad de aquella luz del lenguaje. $\mathrm{Su}$ forma de hacer aparecer no debería entenderse como un exceso luminoso que busca desterrar toda oscuridad para poder hacer algo presente, sino más bien como la luz de una llama que en su brillar permite y convive con las sombras. De modo semejante, para que pueda darse una auténtica conversación necesitamos que el silencio tenga tanto lugar como la palabra, pues él es el que permite el diá del $\operatorname{logos}^{44}$ Entonces, lo que las palabras de las cosas dicen es una

42 H.-G. Gadamer, WM, p. 480; VM, p. 569.

43 Almorín denomina a la hermenéutica una «ontología de la pertenencia», por lo mismo que Grondin le da el nombre de «metafísica de la finitud». Cf. T. E. Almorin, «Ontología y metafísica en algunos textos de Gadamer», Intersticios, Año 6, nº 14-15 (2001), pp. 41-63 y J. Grondin, Introducción a Gadamer, pp. 229 ss.

44 Quedamos aquí en deuda respecto al análisis sobre el lugar del silencio en este lenguaje. El silencio no es en nada ajeno a la tierra de la palabra. Incluso cuando estamos en los terrenos del lenguaje del ser, palabra y silencio no se excluyen, más bien se requieren mutuamente y ambos parecen ser trascendentales. Pues el silencio no es sólo una forma de huída cuando ya nada se puede decir, como el decir tampoco es una incesante victoria sobre el silencio como creería un hombre demasiado locuaz. Todo lenguaje está constituido, como la música, de sonidos y de silencios, y todo ser parece tener necesidad de ambos. $C f$. J. Rassam, Le silence comme intro- 
desproporción de sentido para el enunciado, que es propia de la finitud del aquí y ahora de nuestras palabras, de nuestra comprensión y auto-comprensión. ${ }^{45} \mathrm{El}$ acontecer de este lenguaje dialógico en el que participamos todos los hablantes (cosas y hombres) exige en su infinitud el discurrir de nuestra historicidad, es decir, la tarea de ligar el aquí y ahora para que contenga en sí su pasado y su futuro, haciendo de la situación una situación hermenéutica. Por eso de nuestro lado, es natural que muchas veces nos falten las palabras y descubramos que la auténtica conversación sólo puede tener lugar, no entre personas que saben, sino entre seres que engendran con otros preguntas y que para ello necesitan también escucharse. Así queda en evidencia porque la ontología debe ser necesariamente hermenéutica, y también la profunda vocación metafísica de ésta. El lenguaje es siempre lenguaje de la tierra a la que se pertenece y se cumple en la realización de un progresivo sentirse en casa en el mundo que nunca acaba, pero que tampoco fracasa porque tiene infinitas posibilidades de decir a su alcance. Ese movimiento metafísico que acompañamos con el «constante convertirse en lenguaje de nuestra existencia» lo expresa bien la hermenéutica con la infinitud interior en el hablar del diálogo. ${ }^{46}$

La productividad de sentido que ahora parece contener la famosa frase de la hermenéutica incluye estos nuevos trazos que se sostienen sobre esa antigua y mutua pertenencia ontológica que hoy se presenta en el modo de nuestra finitud como un diálogo interminable (movimiento lingüístico vinculante del preguntar y responder) del que nacen el ser y el comprender de las cosas y de nosotros. Bajo esta dia-lógica, es posible para Gadamer no sólo continuar la labor emprendida por Heidegger de superar la metafísica como onto-teología, sino también recuperar la posibilidad de la metafísica en la forma de una ontología centrada en el interminable diálogo con las cosas y entre nosotros, a cuyo centro reconducimos el concepto de pertenencia. Nos encontramos en los albores de una posible respuesta para la pregunta formulada por Habermas en su trabajo de homenaje a Gadamer: «¿Cómo es posible la metafísica después del historicismo?».47

duction a la métaphysique. Toulouse: Publication Université de Toulouse-Le Mirail, 1980.

45 En este sentido,podríamos releer la sentencia de Wittgenstein referida a que los límites de mi lenguaje son los límites de mi mundo. Hay una parte del suelo del mundo que permanece en las sombras de mi razón y mi lenguaje pero como aquello a lo que ellos pertenecen; a tal extremo que incluso en su infinitud también estoy yo mismo $C f$. J. J. Nebreda, «El ser, que puede ser comprendido, es lenguaje», en El legado de Gadamer. Granada: Universidad de Granada, 2004, pp. 209-224.

$46 C f$.H.-G. Gadamer, «Die Sprache der Metaphysik», en Gesammelte Werke III. Tübingen: Mohr (Paul Siebeck), 1999, p. 236-7; traducción al español «El lenguaje de la metafísica», en Los caminos de Heidegger, traductora A. Ackermann Pilári. Barcelona: Herder, 2002, p. 81.

47 J. Habermas, «¿Cómo es posible la metafísica después del historicismo», en El ser que 


\section{EL SER VOZ DE LA HISTORIA: SU LENGUAJE}

El análisis de la experiencia lingüística hacia el que se dirige todo Verdad y Método está prologado por las consideraciones respecto de la experiencia histórica. De modo que la dimensión metafísica que la hermenéutica adquiere con la centralidad del lenguaje sólo es posible, como hemos visto, gracias a la condición de historicidad y de pertenencia que reconduce al centro del problema durante la segunda parte de la obra. El vínculo entre historia y lenguaje ha sido tema de varios textos tardíos de Gadamer como Histórica y lenguaje (1987), Historicidad y verdad (1991). De manera que tanto la intencionalidad estructural de su obra mayor como la constante temática en sus diversos trabajos justifican, desde el lugar en que ahora nos encontramos, la posibilidad de dar un salto hacia atrás y preguntarnos qué se juega para el ser de la historia en la confrontación de las dos fusiones del lenguaje. A lo largo de sus estudios, Gadamer parece establecer la correlación en dos niveles:

A) En su horizonte semántico más usual, el vínculo entre lenguaje e historia se sostiene sobre el carácter narrativo de cualquier historia, pues «lo que caracteriza a todas nuestras historias y las convierte en tales es el hecho de que las contamos, y contamos estas innumerables historias una y otra vez». ${ }^{48} \mathrm{La}$ condición de posibilidad de su ser es precisamente venir al lenguaje, ser narrada. De modo que la determinación de la palabra en su fusión con el entender hace de la historia nuestra historia y deja en evidencia nuestra doble condición de historicidad y lingüisticidad. Pero cuando nos preguntamos ¿qué es lo que nos atrapa en las historias que escuchamos o contamos? aparece un segundo nivel que implica la superación de esta primera fusión lingüística.

B) Si el lenguaje en el que las cosas vienen al ser «se orienta hacia lo abierto, hacia el todo y hacia la amplitud del tiempo y del futuro, [...] [y] delinea el vasto horizonte del 'ahí' de mundos humanos», ${ }^{49}$ entonces el poder atrayente de una historia radica precisamente en esa presentación que acontece delineándose en la fusión de ser y lenguaje. Por eso, escuchamos a quien narra historias porque entre sus palabras y nuestra escucha llegan al mundo cosas que tienen que ver con nosotros y con las que, de alguna manera, guardamos ese juego de co-pertenencia. Así el análisis de la experiencia histórica en la segunda parte de Verdad y Método puede ser releído a la luz de la significación metafísica

puede ser comprendido es lenguaje. Homenaje a Hans-Georg Gadamer, pp. 97-107.

48 H.-G. Gadamer, «Historik und Sprache», p. 328; «Histórica y lenguaje: una respuesta», p. 104.

49 Ibid., p. 329; p. 106. 
de la máxima hermenéutica que prologa. Entender porque el ser que puede ser comprendido es lenguaje, abre el horizonte de comprensión de la historia en tres sentidos que actuarán a modo de conclusión:

1) La historia debe ser entendida no sólo como aquella historia que nos pertenece en tanto la hacemos y la narramos, sino también, por la condición reversible de pertenencia ontológica y del carácter primario de ser en relación, como aquella a la que pertenecemos en el modo de la tradición. «La pertenencia a tradiciones pertenece a la finitud histórica del estar ahí tan originaria y esencialmente como su estar proyectado hacia posibilidades futuras de sí mismo». ${ }^{50}$ A semejanza de la triple correspondencia de ser-lenguaje-entender, podríamos plantear la co-pertenencia entre ser, historia y comprender. Ella contendría la fusión de la historia y la comprensión que haría referencia a la historicidad de nuestro pensar, pero también la fusión del ser y la historia que indicaría el modo (siempre lingüístico) de las cosas de «venir al mundo», es decir, la historicidad del ser. El carácter trascendental de la historicidad como condición de posibilidad de la comprensión humana impone la pregunta si puede considerarse también como una propiedad trascendental del ser mismo, es decir, como la historia del ser. Según Vattimo, Gadamer no gusta hablar, como tampoco Derrida, de una «historia del ser», tal vez, a causa de su preocupación por dar lugar así una «metafísica historicista». ${ }^{51}$ Pues si la expresión fuese «el ser es historia», él parecería reducirse a sus interpretaciones aquellas de una época o de una cultura determinada (el acento sobre la historia nos descubre una vez más la vocación nihilista de la hermenéutica). Pero si se pone el acento del otro lado de esta nueva pareja hermenéutica, «el ser es historia» hace referencia entonces a «una historia de las cosas». No hay aquí historicismo. Hay más bien una metafísica de otra tonalidad que podría responder a la pregunta de Habermas. Esta dirección de sentido podría indicar Gadamer cuando afirma que «en realidad no es la historia la que nos pertenece, sino que somos nosotros los que pertenecemos a ella».52 El actuar de su poder sobre nosotros se deja ver en el modo de la eficacia histórica (Wirkungsgechichte) a un punto que ni siquiera imaginamos, pues llega a ser «más ser que conciencia». ${ }^{53}$ La fórmula, que recuerda extrañamente a Marx, indica los límites epistemológicos y ontológicos de la soberanía

50 H.-G. Gadamer, WM, p. 266; VM, p. 328.

51 G. Vattimo, «Historia de una coma. Gadamer y el sentido del ser», p. 61.

52 H.-G. Gadamer, WM, p. 281; VM, p. 344.

53 Que la conciencia de la eficacia histórica no sólo sea producto de la historia que hacemos sino también a la que pertenecemos, deja en claro que tipo de identificación hay en nosotros entre Wikungsgechichte (eficacia histórica) y de Wirklichkeit (realidad). Cf. H.-G. Gadamer, «Rhetorik, Hermeneutik und Ideologiekritik. Metakritische Erörterungen zu Wahrheit und Methode», en Gesammelte Werke II, p. 247; traducción al español «Retórica, hermenéutica y crítica de la ideología. Comentarios metacríticos a Verdad y Método I», en Verdad y Método II, p. 239. 
de la subjetividad, ya que no sólo lo que ella comprende desde el horizonte de precomprensión de sus prejuicios, sino lo que ella es, en la realidad histórica de su ser, depende menos de su conciencia que de su determinación por parte de la historia a la que pertenece.

2) Nuestro previo y siempre más originario ser en relación de pertenencia al lenguaje y a la historia parecen condensarse para Gadamer en la condición inmemorial de nuestro propio ser finito, en tanto inmemorial es lo anterior a todo pensamiento que se une consigo mismo en el constante convertirse en lenguaje de nuestra existencia. En él acontece el lenguaje de las cosas y de sus posibilidades como la vivacidad de la voz propia de una tradición a la que pertenecemos. Entonces la tesis fundamental de que el lenguaje determina (bestimmt) a la vez el proceso y el objeto de la comprensión, tal vez deba entenderse en el sentido que el verbo alemán be-stimmen tiene de «dar voz a»; una vocalidad que podría compartir aquel doble carácter trascendental del lenguaje. Curiosamente la palabra que en su luz da voz a las cosas históricas se dirige a nosotros en la vivacidad de un tono familiar que también busca ponernos en diálogo.

3) El ser voz de la historia concuerda y corresponde con el cumplimiento del lenguaje del ser en su ser diálogo. Ambos se manifiestan en el mutuo reconocimiento: «nos reconocemos en lo otro, en lo otro de los hombres, en lo otro del acontecer». ${ }^{54}$ El reconocimiento de su voz es indispensable para el diálogo. Presupone la distancia, pero simultáneamente la anula porque somos participantes de una conversación, de un juego que el lenguaje de las cosas y la historia juegan con nosotros. Cuando narramos y escuchamos historias colaboramos en la construcción de una comunidad basada en lo que tiene sentido para nosotros. Dirigimos nuestra comprensión dialógica hacia lo que todos tenemos en común y reconocemos en el otro mejor que en nosotros mismos.

Es cierto que las historias de las que procedemos pueden ser una condena o un contrapeso de resistencia del que quisiéramos librarnos y no el hablar vivo de la voz del pasado aún presente al que prestamos atención para abrir las posibilidades de nuestro futuro. Precisamente, que el hombre sea un animal racional, que posee lenguaje, como dice Aristóteles, significa que «busca siempre el sentido que le permite abrir constantemente, en medio de la insensatez del acontecer y de la historia, algo parecido a horizontes de expectativa, de esperanza, de osadía y de no abyección» ${ }^{55}$ Las resistencias del sinsentido recuerdan porque en verdad nunca seremos dueños de la historia, del mismo modo, que nunca cerraremos el diálogo y el juego con el lenguaje al que estamos siempre invitados porque a él pertenecemos inmemorialmente.

54 H.-G. Gadamer, «Historik und Sprache», p. 329; «Histórica y lenguaje: una respuesta», p. 105.

55 Ibid., p. 325; p. 100. 
Francisco Díez Fischer es profesor en la Facultad de Derecho de la Universidad Católica Argentina y becario CONICET.

Línea de investigación:

La noción de oído interior en la estética y la filosofía hermenéutica de Hans-Georg Gadamer.

Publicaciones recientes:

«Kairós, arte y celebración en la filosofía de Hans-Georg Gadamer», Intercambio, Tübingen, (2006), pp. 161-173.

«La eficacia histórica de la confesión como género autobiográfico de la conciencia», en Actas de las III Jornadas Nacionales de Filosofía Medieval, Formato Digital, Buenos Aires, (2008), ISBN: 978-987-537-072-2.

«La eficacia histórica del clima y del paisaje», en Revista Humanistas, Pontificia Universidad Católica del Perú, (2008).

«La operatividad de la eficacia histórica (Wirkungsgechichte) en su dimensión ambiental», en Acta Fenomenológica Latinoamericana, Perú, (2008).

Dirección postal:

Bouchardo 2032, Castelar, Buenos Aires, Argentina. (C.P.: 1712)

Correo electrónico: franciscodiezfischer@gmail.com 
